\title{
Comparative Study on the Design Features of "Umbrella Pattern" Images on Eastern and Western Porcelain
}

\author{
Lejun $\mathrm{Liu}^{1, *}$ Jingxin $\mathrm{Gu}^{1}$ \\ ${ }^{1}$ Jingdezhen Ceramic University, Jingdezhen, Jiangxi 333403, China \\ "Corresponding author. Email: llj7822000@126.com
}

\begin{abstract}
In the Ming and Qing Dynasties, the image of "umbrella pattern" was popular on porcelain. With the export of Chinese porcelain, the decorative patterns were also learned and imitated by various countries, and the image of "umbrella pattern" was also among them. Given the popularity of "Chinese style", Western porcelain absorbed oriental culture and combined with their own artistic characteristics to innovate umbrella pattern image. In this paper, comparative study of the "umbrella pattern" image on the eastern and Western porcelain are conducted combining the background of its rise to comb the design performance characteristics of the "umbrella pattern" image on the eastern and Western porcelain and sum up the similarities and differences of the "umbrella pattern" image design on the eastern and Western porcelain, so as to provide reference for the application form of the eastern and Western art exchange.
\end{abstract}

Keywords: Eastern and Western, "Umbrella pattern" image, Design features, Comparative study.

\section{INTRODUCTION}

The image of "umbrella pattern" on Chinese porcelain is often expressed in the form of Buddhist auspicious patterns or the ceremonial instruments used by nobles to travel. The 17th-18th century was the heyday of porcelain trade between the East and the West. Yingrun exquisite Chinese porcelain was deeply loved by all countries. The European aristocracy's infatuation with porcelain led the whole western market to rush to buy Chinese porcelain. Chinese culture was also brought into the West with porcelain as the carrier. Europeans defined the artistic style with oriental characteristics as "Chinese style", which was widely used in the creation of Western art at the same time. The Chinese royal aristocracy in the imagination of westerners is leisurely and wealthy. They are dressed in gorgeous silk long shirts, wearing pointed conical caps, followed by attendants who take umbrellas to shade them, and servants who hold fans to cool them. In this way, Westerners think that the umbrella cover on Chinese porcelain over the heads of emperors and nobles is the standard configuration of the powerful Chinese, so the image of "umbrella pattern" has become one of the representative elements of Chinese style to a certain extent, and has been widely used.

At the turn of Ming and Qing Dynasties, the Qing government carried out the policy of banning porcelain from the sea. The huge demand for porcelain in the western market could not be met, so it had to turn to Japan, where the level of porcelain making was on the rise at that time. At first, the west only asked them to copy the style of Jingdezhen export porcelain, among which there were similar umbrella patterns; after 1684, more ukiyo umbrella beauty patterns began to appear on Japanese porcelain, which further determined the formation of Japanese ceramic art style. As a result, the umbrellas on the eastern and Western porcelains shine brightly in their respective cultural environments and interact with each other in cultural exchanges. The umbrellas on Western porcelains are more of a blend of the image features of China and Japan, and have their own artistic characteristics 


\section{THE PERFORMANCE CHARACTERISTICS OF "UMBRELLA PATTERN" IMAGE ON ORIENTAL PORCELAIN}

The different expression of umbrella pattern image on Oriental porcelain is mainly due to the different understanding and application of umbrella culture in different countries. For example, Chinese umbrellas are Buddhist instruments and ceremonial items, while Japanese umbrellas are mostly used for performance. The differences in performance are obviously influenced by social and cultural factors. This chapter will focus on the analysis of the image of "umbrella pattern" in China and Japan. This paper analyzes the characteristics of porcelain in Japan and the relationship between them.

\subsection{Characteristics of "Umbrella Pattern" Image on Chinese Porcelain}

The traditional "umbrella pattern" image on Chinese porcelain is different from the shape of umbrella in our cognition. It is usually a dome rather than a spire. Yellow satin is stretched on the umbrella frame, and a curtain is set around the ribs. The curtain is decorated with pleated cloth or fringes. In the early days, this kind of umbrella was called "treasure umbrella", "canopy" or "canopy". This is related to its use, this form is more solemn than the ordinary rain parasol. In ancient China, the umbrella was not only used as a practical tool to shelter the wind and rain, but also a magic tool of Buddhism and Taoism, as well as an instrument of honor for princes and Marquises to travel. The Eight Buddhist auspicious patterns prevailing on Ming and Qing porcelains are composed of Falun, Faluo, Baosan ("Figure 1"), White cap, lotus, Aquarius, goldfish, intestines.

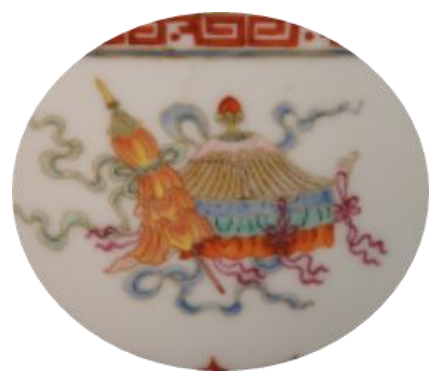

Figure 1 A part of the eight treasures bowl of Kangxi in Qing Dynasty collected in the Palace Museum.

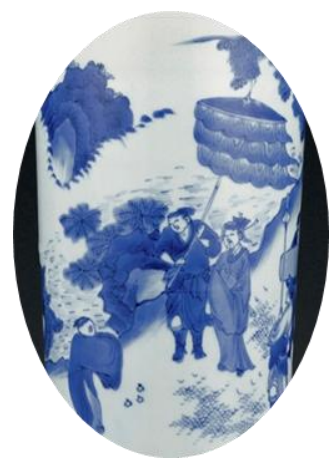

Figure 2 The figures of Emperor chongzheng of Ming Dynasty who visited sages (part).

There is a saying in the astrology of Taoist culture that all the people under it are sages. This may be related to the fact that umbrellas were used for the travel of emperors and nobles. On the blue and white picture bottle of Emperor Wen's visit to sages made in the Chongzhen period of Guan Ming Dynasty, a treasure umbrella with three layers of curtains ("Figure 2") is depicted, which accounts for a certain proportion in the picture, and sets off the majesty and status of the emperors standing under it. A large part of the Ming and Qing porcelains depict the outdoor travel scenes of high officials and dignitaries Set off by the Baosan.

\subsection{Characteristics of "Umbrella Pattern" Image on Japanese Porcelain}

The images of "umbrella pattern" on Japanese porcelain can be roughly divided into two categories according to the information I have now. The "umbrella pattern" images on Japanese porcelain can be roughly divided into two categories according to the information I have now. The first is the imitation and creation of Jingdezhen export porcelain; the second is the ukiyo painting of umbrella holding beauty inspired by its own culture. To be sure, these two categories cannot be treated separately, and the fusion and reference between them cannot be ignored. This is only for the better division of images. 


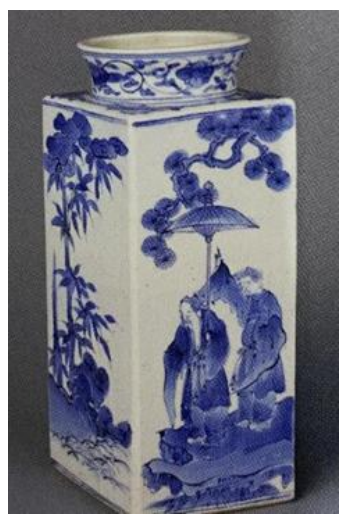

Figure 3 Panasonic figure square bottle in the late 17 th century.

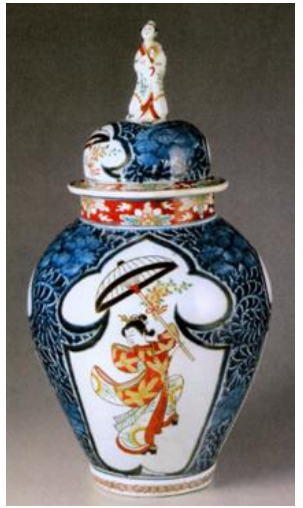

Figure 4 In the middle of the 18th century, Imari umbrella holding beauty pot $\mathrm{H}$ : $59 \mathrm{~cm}$.

In the late 17th century, Japan made a square bottle with Panasonic figure pattern ("Figure 3"). The bottle is painted with a tall man standing under a pine tree with an umbrella. The attendant behind raises his hand to show his opinion. The bottle is painted with pine on one side and bamboo on the other. The appearance of pine and bamboo together with Gaoshi in Chinese porcelain shows its noble and resolute character. It also has the same meaning in Japan, which is influenced by ancient Chinese culture. Obviously, this porcelain was created under the influence of Chinese decorative images, adding the dynamic of Gao Shi's umbrella, which means that it is "too high to be cold".

In addition, the colorful umbrella holding beauty pot ("Figure 4") made in Japan's YODA area depicts a beauty dancing with an umbrella at Kaiguang. She stands on one foot, waving her hand and umbrella in a dynamic and beautiful way, which is a typical type of Japanese ukiyo dancing beauty. The Japanese umbrella making technology was brought back from China by the envoys sent to Tang Dynasty. It was first used as a tool to shelter the wind and rain, and then developed into a performance prop of tea art and dance, and finally became one of the symbols of traditional Japanese culture.

\section{DESIGN FEATURES OF "UMBRELLA PATTERN" IMAGE ON WESTERN PORCELAIN}

With the prosperity of cultural exchanges between the East and the west, the "Chinese style" art is highly praised in Europe, and the "umbrella pattern" image design on Western porcelain reflects the influence of Oriental elements everywhere. However, any country always shows the transformation of its own culture while accepting foreign culture. Therefore, the image of "umbrella pattern" on Western porcelain has traces of Western art and aesthetic habits. This chapter analyzes the influence of Oriental elements and Western art style on the "umbrella pattern" image design, in order to explore the design characteristics of the "umbrella pattern" image on Western porcelain in detail.

\subsection{Image Design Features of European "Umbrella Pattern" Under the Influence of Oriental Elements}

Among the many oriental elements, the closest to the image of "umbrella" is undoubtedly that the top of Chinese pagodas and pavilions are shaped like a sharp cone. When Chinese style prevails, Westerners will not ignore the attention of traditional Chinese architecture. This novel architectural style has deeply attracted Westerners. European countries have built palaces and teahouses imitating Chinese pavilions or pagodas. The famous English chipendale furniture made a kind of Chinese chair at that time. The top of the chair back was in the shape of a pavilion roof. It can be seen that Western designers did apply the popular Chinese architectural features to the design of other crafts. Domestic scholars have long proposed that Chinese pagodas are closely related to Indian umbrellas. It is not a fantasy that the design of umbrellas on Western porcelain should learn from the top shape of traditional Chinese architecture.

The other is the influence of Chinese canopy on the image design of umbrella pattern on Western porcelain. As mentioned above, the canopy, as a necessity for the travel of dignitaries, is different from the ordinary umbrella. The most prominent feature is the long handle dome, with curtains or tassels hanging at the edge, and most of them have two or more layers (the more layers of the canopy, the more dignified they are). Most of the porcelains 
exported to Europe have scenes of nobles traveling with umbrellas, so it is natural to imitate the image of Oriental umbrellas. Worcester porcelain factory produced a piece of porcelain in 1755 ("Figure 5"). It is painted with a figure with a high nose and long curly hair. It looks like a European, but it wears a conical official hat, Chinese clothes and a moustache. Therefore, it is speculated that it is a Chinese, but the western painters have not painted the face of an oriental. There is a humble servant with a fruit basket behind the protagonist, so it can be judged that the image cup in the British Museum may be intended to express the story of a well-known Chinese official.

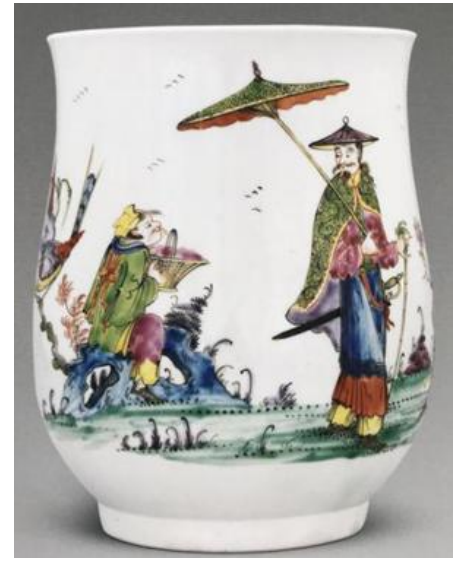

Figure 5 The figure cup made by Worcester porcelain works, British Museum Collection.

\subsection{The Influence of Western Art Style on the Image Design of "Umbrella Pattern" on European Porcelain}

The image of "umbrella pattern" was popular in Western porcelain during the 17th-18th century when "Chinese style" prevailed. During this period, Baroque and Rococo art were all the rage in Europe. The image design of "umbrella pattern" on European porcelain not only had the reference of Oriental elements, but also had a strong Western artistic style.

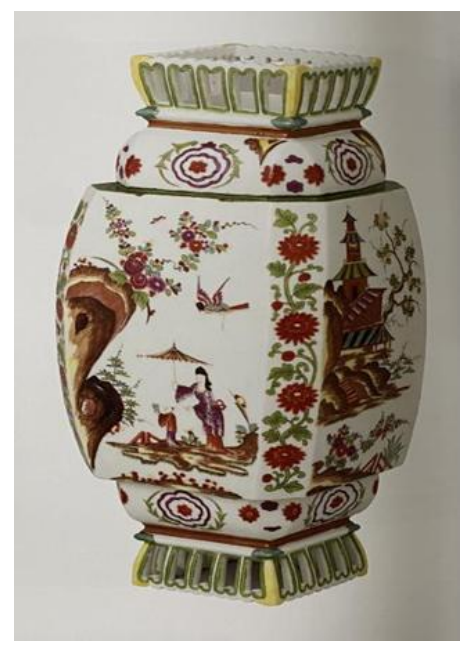

Figure 6 Meissen imitation of Chinese lampshade in Dresden National Art Museum collection.

Chinese style, Baroque and Rococo art can be regarded as parallel in the same era. At that time, the West was full of yearning and worship for the mysterious oriental powers. The Chinese goods brought back by the ocean going fleet were exquisite and luxurious in their eyes. This kind of cognition was highly consistent with the luxury and romance advocated by Baroque art. In 1727, Meissen, Germany produced a square lampshade ("Figure 6"), which was modeled after the Chinese candlestick. It was a kind of irregular shape. On the front of the candlestick is a woman holding an umbrella for a child playing in front of her. The umbrella in the woman's hand is painted with the classic red, yellow and purple of Meissen porcelain, which is in harmony with the overall color of the picture. The fringe of the umbrella is decorated with tassels. In addition, the surrounding environment is red and willow green, and the side of the candlestick stands in the courtyard, which makes the picture gorgeous. The combination of modeling and decoration makes this work have the style of Baroque art.

\section{SIMILARITIES AND DIFFERENCES OF "UMBRELLA PATTERN" IMAGE DESIGN FEATURES BETWEEN EASTERN AND WESTERN PORCELAIN}

The "umbrella pattern" images on the eastern and Western porcelains are all originated from China. Therefore, they have essentially the same form of use. They are used to express the necessities of aristocratic life, and the entourage often takes the umbrella for the protagonist. This form of application is the most prominent in China. Chinese porcelain 
always depicts the emperors and nobles with outstanding colors or enlarged proportions. The umbrella covers are almost multi-layered. The overall momentum is huge and the class is distinct. In Japan, it is weaker. In addition to completely imitating the type of Chinese porcelain, this kind of image on Japanese style porcelain is random, and the definition of servant and master is weakened, sometimes the two will be parallel in the picture. There are also such things as the obvious size of the primary and secondary characters, which mainly appear in the image of the umbrella holding beauty painted in ukiyo, such as an Imari porcelain used for export.

The purpose of the umbrella pattern in Japan and China is different, which is due to the cultural differences between China and Japan. What's more, in the west, they have a weak sense of hierarchy. In their eyes, umbrellas are just tools to represent the Oriental people. It doesn't matter whether they show their momentum or not. Therefore, because they don't understand the oriental culture, the umbrellas on Western porcelain are one of their characteristics, just like the cups produced by Worcester porcelain factory, The characters and umbrellas are incomplete imitations of China, and the feeling of the image to the viewer is only the expression of Chinese style image, which has nothing to do with highlighting the dignity of the protagonist.

Generally speaking, the starting point of using the umbrella pattern image on Eastern and Western porcelain is the same, but due to the different ideological and cultural backgrounds of different countries, the final image design and presentation of the picture effect are different.

\section{CONCLUSION}

The image of "umbrella pattern" on Eastern and Western porcelain is different in different countries' Ideological and cultural environment. This kind of image on Chinese porcelain is the expression of traditional culture and religious color; Japan has created a new form of artistic expression for it; with the East-West trade, it has become an important element of European "Chinese style" design. Its different image expression in the East and the west is the result of different cultures' innovative application of the same thing. Through the comparative study of the image design features of "umbrella pattern" on Eastern and Western porcelain, we can find that different cultures have strong inclusiveness and the same thing In the case of a certain ideological fit, we can still inherit and develop innovation in different cultures.

\section{AUTHORS' CONTRIBUTIONS}

Lejun Liu contributed to revising and editing, while Jingxin $\mathrm{Gu}$ wrote the manuscript.

\section{REFERENCES}

[1] Hong Ying. Japanese umbrella culture [J], World Culture. 2009, issue 08.

[2] Zhang Ye research on the application of Chinese traditional cultural elements in western design circles [J] Journal of Nanjing Academy of Arts (Art and Design). Issue 03, 2019.

[3] Zhang Jing, Zhao Bofei. Aesthetic consciousness of Chinese umbrella culture [J]. Journal of Shaanxi Preschool Normal University. 2018 (9).

[4] Wang Caiyong. Three ways for Chinese art to enter Mason's porcelain painting .Henan Social Sciences, 2019, issue 12.

[5] Yuan Xuanping. Chinese style design in Europe from 17 th to 18 th century [D]. Heritage Press, 2005.

[6] Yu Chunming's Chinese business card the origin and collection of Ming and Qing porcelain for export [D] Xinzhi Sanlian bookstore. 2011. 